\footnotetext{
* Graduado em Direito pela Universidade do Vale do Itajaí; Mestre e Doutorando em Ciência Jurídica pela Universidade do Vale do Itajaí. E-mail: staffen sc@yahoo.com.br ** Graduado em Direito e em Filosofia pela Universidade Federal de Santa Catarina; Mestre em Direito pela Universidade Federal de Santa Catarina (2002); Doutor em Direito pela Universidade Federal de Santa Catarina. Docente Titular nos Cursos de Mestrado e Doutorado do Programa de Pós-Graduação Stricto Sensu em Ciência Jurídica na Universidade do Vale do Itajaí. E-mail: pmabreu@brturbo.com.br
}

\section{Reflexões sobre o modelo participativo de Processo Jurisdicional Brasileiro}

\section{REFLECTIONS ON PARTICIPATORY MODEL OF Brazilian Judicial Process}

\author{
Márcio Ricardo Staffen * \\ Pedro Manoel Abreu **
}

Resumo: O presente artigo científico tece algumas considerações sobre o modelo participativo de processo jurisdicional brasileiro, comungando, para tanto, a noção de status activus processualis e a possibilidade do seu exercício em um cenário jurisdicional marcado pelo dualismo procedimentalismo versus substancialismo. Para tanto, estuda-se de forma sucinta as principais características das teorias procedimentalista e substancialista no intuito de conceber o processo como uma instância irrenunciável de participação e inclusão substancial das partes. Utilizou-se, para o desenvolvimento desta presente pesquisa, o método indutivo, operacionalizado pelas técnicas de conceitos operacionais e da pesquisa bibliográfica.

Palavras-chave: Processo jurisdicional; Participação; Procedimentalismo; Substancialismo; Status activus processualis.

Abstract: This research paper examines the notion of status activus processualis and the possibility of its exercise in a scenario marked by jurisdictional dualism proceduralism versus substantialism. To this end, we study briefly the main features of the theories and proceduralist substantialist in order to design the process as an indispensable body of participation and inclusion of substantial parts. It was used for the development of this research, the inductive method, operated by the techniques of operational concepts and literature.

Keywords: Status activus processualis; Proceduralism; Substantialism. 


\section{INTRODUÇÃO}

O presente artigo propõe-se a apresentar algumas reflexões sobre o modelo participativo de processo jurisdicional brasileiro em conexão com a noção de status activus processualis e a possibilidade de seu exercício em um cenário marcado pelo dualismo procedimentalismo versus substancialismo, nos contornos do Estado Democrático de Direito.

As reflexões que seguem, estão por aí, abertas ao diálogo daqueles que se encontram, de certa forma, incomodados pela maneira exclusivamente formal do processo. Apesar de o processo dialogar com outros elementos, o lugar democrático que ocupa é de fundamental relevância, juntamente com o critério ético, uma vez que são as duas importantes possibilidades democráticas de inclusão.

Com efeito, a concepção de processo trabalhada pelo senso comum teórico dos operadores do direito é a de compreender o processo como um conjunto de atos preordenados a um fim, ou seja, a atividade exercida pelo julgador no exercício da jurisdição, sendo o procedimento seu aspecto meramente formal, o rito a ser estampado. A preservação da divisa "lei é lei e ponto final" sobre vários aspectos sustenta o fenômeno da modernidade tardia, conforme Streck, que expõe o inadimplemento escancarado das promessas da modernidade e, onde vislumbra-se uma desfuncionalidade do Direito e das instituições encarregadas de aplicar a lei em face da constante preocupação pela manutenção do establishment.

A máxima processual de que os fins justificam os meios [visão instrumentalista] é geradora da ineficácia de grande parcela da tutela jurisdicional produzida pelo error in procedendo da maior parte das decisões proferidas que no intuito de satisfazer o fetiche da efetividade, da compulsão pelas metas, “deletam" o devido processo legal. O processo não pode[rá] ser a canalização da vontade dominante, a síntese (sem antítese) das opções axiológicas de uma sociedade excludente de pensamento único ditada por um juiz. Respostas jurisdicionais mais efetivas necessitam de uma nova construção processual, apta a solucionar os problemas da atualidade. Pois, como é sabido, as questões do século XXI são discutidas, ainda a partir da lógica jurídica do século XVIII, lecionada nos moldes elaborados pelos glosadores medievais.

Com urgência, na perspectiva do Estado Democrático de Direito, é preciso mirar como norte a inclusão e a participação substancial dos destinatários da decisão jurisdicional. Afinal, o que caracteriza as democracias atuais é o relacionamento entre os indivíduos e o Estado. Um sistema de direitos de uma 
democracia não se exaure apenas na proteção individual contra a invasão dos poderes públicos. Aos indivíduos é garantida a inclusão e a participação. Esse é o desafio.

\section{A DUALIDADE DO MODELO PARTICIPATIVO: procedimentalismo versus substancialismo}

Para uma explanação que trate das possibilidades de efetivação das disposições constitucionais, e que analise o papel do Judiciário, quanto a uma possível postura pró-ativa (intervencionista) e no que tange à sua alegada falta de legitimidade e representatividade política, torna-se de fundamental relevância ter ciência, ainda que superficialmente, a partir da proposta de Vianna, de duas correntes de análise: o procedimentalismo (Habermas-Garapon) e o substancialismo (Cappelletti-Dworkin). Ressalte-se, ab initio, que o objetivo deste estudo não é determinar qual o melhor eixo de pensamento, mas revisar a atuação do Poder Judiciário em sociedades de foraclusão, como o Brasil, almejando a efetivação dos Direitos Fundamentais.

O procedimentalismo capitaneado por Jürgen Habermas e Antoine Garapon, posiciona-se contrário à invasão da política e da sociedade civil pelo Direito. Em Habermas, o procedimentalismo almeja transcender a crise do Estado de Direito e o antagonismo entre o modelo liberal e o paradigma social, através do princípio democrático-deliberativo. Desta forma, a razão instrumental (cartesiana) é desfeita em favor de uma razão comunicativa-emancipatória.

Para tanto:

Habermas utiliza sua teoria do discurso, tratando de um 'agir comunicativo' legitimador da vontade coletiva, como referencial teórico para sustentar a defesa de um novo paradigma, o procedimental-deliberativo, que atribui ao poder legislativo a função central do Estado Democrático de Direito. O poder judiciário, neste caso, ficaria relegado às funções garantidoras dos procedimentos legislativos de formação majoritária da vontade. ${ }^{1}$

Esse agir comunicativo, por seu turno, leva em conta o entendimento lingüístico com instrumento de coordenação da ação, propiciando que as suposições contrafactuais dos atores que orientam seu agir por pretensões de validade ganhem relevância imediata para a construção e a preservação de

${ }^{1}$ MARCELLINO JUNIOR, Julio Cesar. Princípio constitucional da eficiência administrativa (des)encontros entre economia e direito. Florianópolis: 2009, p. 160. 
ordens sociais, pois estas se mantêm no modo de reconhecimento de pretensões de validade normativa. Assim, o conceito nuclear de "agir comunicativo explica como é possível surgir integração social através de energias aglutinantes de uma linguagem compartilhada intersubjetivamente."

Neste cenário, Habermas entende que na vigência do Estado Democrático de Direito, os Tribunais Constitucionais necessitam abarcar uma postura de compreensão procedimental da Constituição. Assim, o Judiciário num todo, dever-se-ia abolir da visão autoritária que entende a Constituição como ordem concreta de valores, para concebê-la como mecanismo de condições processuais de matriz democrática das leis que garantem a legitimidade do Direito. Nesta percepção, o Poder Judiciário deveria apenas "zelar pela garantia de que a cidadania disponha de meios para estabelecer um entendimento sobre a natureza dos seus problemas e a forma de sua solução".

Garapon, por seu turno, teoriza o prejuízo que a ingerência interventiva do Poder Judiciário causa sobre a sociedade e a política, determinando que este processo causa inevitável erosão da democracia representativa. Aqui, duas observações necessitam emergir. Primeiro, Garapon, tem sua fala localizada na tradição estatal francesa, onde o Judiciário não é forte e o Legislativo ocupa posição privilegiada na cultura político-democrática daquele país. Segundo, em termos gerais a ideia de democracia representativa é um conceito débil e impotente no mundo ocidental que reclama uma nova construção. Ainda assim, sustenta que:

O excesso de Direito pode desnaturalizar a democracia; o excesso de defesa, paralisar qualquer tomada de decisão; o excesso de garantia pode mergulhar a justiça numa espécie de adiamento ilimitado. De tanto ver tudo através do prisma deformador do Direito, corre-se o risco de criminalizar os laços sociais e de reativar o velho mecanismo sacrificial. A justiça não pode se colocar no lugar da política; do contrário, arrisca-se a abrir caminho para uma tirania das minorias, e até mesmo para uma espécie de crise de identidade. Em resumo, o mau uso do Direito é tão ameaçador para a democracia como seu pouco uso.

A preocupação de Garapon reside justamente na transferência dos ideais de democracia do Legislativo para o Judiciário, com uma forte articulação entre justiça e democracia, sendo que a primeira categoria passa a ser o referencial de idoneidade da democracia. Assim, o território simbólico da democracia transfigura-se silenciosamente do Estado para a Justiça. Neste espaço provedor, o Estado é o todo-poderoso e pode tudo preencher e corrigir. 
Pela inadimplência das promessas, a esperança se volta à justiça. O sucesso da justiça é diametralmente oposto ao descrédito que toma de assalto as instituições políticas clássicas, causado pela crise de desinteresse e pela perda do espírito público.

Nesta óptica, o Poder Judiciário estaria adstrito ao mero papel de garantidor do circuito "sociedade civil - partidos - representação - formação da vontade majoritária" (VIANNA), onde a legitimação se dá pelo procedimento. Pelo eixo procedimentalista a invasão da política pelo Direito, ainda que justificada por pretensões igualitárias ensejariam em produtos indesejados: a perda de liberdades; o gozo passivo de direito; a privatização da cidadania; e o paternalismo estatal, que "em nada propícia a uma cultura cívica voltada ao fortalecimento das instituições da democracia."

O eixo substancialista posiciona-se de maneira a entender que o Poder Judiciário não deve assumir uma condição passiva diante da sociedade, constituindo-se em um verdadeiro e legítimo garantidor da efetividade constitucional. Em linhas gerais, os substancialistas defendem a concretização dos Direitos Fundamentais construídos e compartilhados pelo cidadão com a chancela do Poder Judiciário.

Esta expansão do Judiciário se comparado com o Legislativo, resultado direto do crescimento do Estado frente à sociedade, pode ser em grande parte também atribuída ao progresso da função interpretativa-criadora do magistrado. Este papel interpretativo do juiz é visto como produto de um ato complexo que requer a devida confluência entre direito, moral, política, equidade, aliada numa postura interdisciplinar, que autorize o direito a permutar informações com outras áreas do conhecimento. Assim, o juiz perde o modelo clássico-positivista de julgamento ao possuir uma presença ativa no que tange à produção do Direito, sem se equiparar, contudo, ao legislador.

A proposta dworkiniana, em sua posição liberal-contratualista, no âmbito da common law, se aproxima do eixo substancialista por conceber a função judicial e a jurisprudência por ela produzida como importante mecanismo de efetivação da comunidade política. O Direito, segundo Dworkin, seria muito mais do que meras regras cuja validade dependeria da aceitação da comunidade como um todo. Desta forma, pela Constituição impõe-se a necessita de uma leitura de certos valores morais consagrados que devem ser reconhecidos e respeitados pela legislação infraconstitucional e pelas decisões jurisdicionais. Neste cenário o intérprete e o aplicador do direito devem assumir uma postura ativa e construtiva. 
Nos dizeres de Streck, o modelo substancialista, opera na perspectiva de que a Constituição estabelece as condições do agir político-estatal, a partir do pressuposto de que a Constituição é a materialização do contrato social. Por isso, o Poder Judiciário não pode ausentar-se diante da sociedade. No caso brasileiro de modernidade tardia, "surge o Judiciário como instrumento para o resgate dos direitos não realizados."

Sobre esta nova postura do Judiciário leciona Abreu:

O momento da consolidação da democracia política no Brasil é a hora da convocação do Poder Judiciário a um ativo protagonismo institucional, não apenas porque a ele cabe a preservação do cânon republicano do equilíbrio entre os poderes, mas também porque a própria sociedade, ao realizar um movimento afirmativo de explicitação de interesses e de demanda por cidadania, vem conhecendo o caminho dos tribunais.

Com isso, a atividade judicial não se limita às funções meramente declarativas do direito, "impondo-se, entre os demais Poderes, como uma agência indutora de um efetivo checks and balances", passando assim, a assumir a missão de guarda das promessas constitucionais, em meio ao mundo laico de interesses e da legislação ordinária, os juízes "seriam os portadores das expectativas de justiça e dos ideias da filosofia".

Enfim, uma república como a brasileira que nasceu sem cidadãos, e "onde o Estado é tudo porque a sociedade é nada", a iniciativa de restaurar e [re]valorizar a sociedade não pode ficar vinculada a métodos usuais de formação da opinião pública onde, com freqüência impera a manipulação da informação, o coronelismo e o clientelismo. Deve sim, o Judiciário, sem se substituir à política, sanar o vácuo deixado pelos demais poderes, concedendo consistência democrática a um excedente de soberania popular que transcende a simplória visão de sufrágio. Para tanto, com urgência é preciso mirar a [re]construção de uma categoria esquecida: o status activus processualis.

\section{O STATUS ACTIVUS PROCESSUALIS}

A análise histórica dos vários modelos de processo demonstra como o processo tem refletido os valores sociais oficialmente tolerados pelo Estado. Grosso modo, o paradigma inquisitorial tipifica a essência de um Estado autoritário, a matriz individualista repete a orientação liberal, e assim por diante... 
Por sua vez, um Estado verdadeiramente Democrático de Direito, como consagra a CRFB/1988, reclama um processo pautado pela inclusão e participação. Sem um modelo processual aberto à dialeticidade não há como se falar em Estado Democrático de Direito. Eis o calcanhar de Aquiles. A teoria geral de processo dominante sustenta a prática de um sincretismo processual impraticável. A variada gama de direitos coletivos, difusos e individuais homogêneos, típicos do Estado Social e da Pós-Modernidade não pode ser acionada, exclusivamente, via institutos processuais individuais. A continuidade deste mo[vi]mento importa no agravamento progressivo da modernidade tardia brasileira, no sentido de incluir os incluídos e excluir os excluídos.

Paralelo ao avanço deste modelo de exclusão surge o ideal de status activus processualis preocupado com a inclusão e participação dos indivíduos no processo jurisdicional. $\mathrm{O}$ advento desta noção de cidadania se atribui a Peter Häberle que, nos idos de 1975, propôs a adoção da categoria status activus processualis para satisfazer a crise de efetividade dos Direitos Fundamentais haja vista a debilidade dos conceitos tradicionais da teoria geral do processo para dar conta desta espécie de direitos. É um claro contraponto ao status negativus, de origem liberal, ao almejar "uma jurisdição aberta institucional e operacionalmente aos argumentos e à participação democrática", segundo o magistério de Abreu, que vai além da mera legitimação para o judicial review.

Assim, pode-se atribuir a noção de status activus processualis a função de realização dos direitos, dotada de uma dimensão além da tradicional ideia de caráter negativo (de defesa), haja vista sua destinação promocional de inclusão e participação no processo. Destarte, desempenha um importante papel teóricodogmático de realização e consolidação da democracia, numa perspectiva participativa e interessada na res publica. A participação dos titulares dos Direitos Fundamentais nos procedimentos públicos de decisão que interferem no conteúdo destes direitos se convertem em instrumento de abertura da Constituição, promovendo, portanto, a integração da Sociedade Civil com a Constituição.

Ressalte-se que, a defesa de um status activus processualis não está adstrita ao imaginário acadêmico ou as lições doutrinárias. Ele, o status activus processualis é produto imediato dos valores mais caros estipulados na Constituição da República Federativa do Brasil de 1988, portanto, garantia constitucionalmente que tutela, ainda que implicitamente, a saber: a instituição de um Estado Democrático, cujo poder emana do povo, destinado a assegurar o exercício dos direitos sociais e individuais, a liberdade, a segurança, o bemestar, o desenvolvimento, a igualdade e a justiça como ideais supremos de uma 
sociedade fraterna, pluralista e sem preconceitos, fundamentada na soberania [popular], na cidadania, na dignidade da pessoa humana e múltiplos direitos deles decorrentes.

Nestes termos, não seria correto que a Constituição estabelecesse valores para ordenar a vida em sociedade e não estabelecesse condições hábeis de acesso à sua efetivação e satisfação. Por isso, o processo deve se aprumar no paradigma de Estado Democrático de Direito, regido por um corpo construtivo e participativo na bricolage das respostas jurisdicionais.

Pela lavra de Abreu, a participação da sociedade civil é decisiva para a efetivação dos direitos constitucionais. Com ela, o conceito de cidadania é transmutado da recorrente e limitada visão minimalista de que democracia equivale a eleições, para uma dimensão ativa, promocional, de participação. $\mathrm{O}$ Estado não pode abrir mão desta participação. A participação dos indivíduos é fundamental para que tenham a plena convicção de que no processo tudo acontece pelo esforço sério, justo e intenso na investigação dos fatos e na busca da justiça para que tenham certeza que a ajuda das instituições em especial do Poder Judiciário repercutirá positivamente na proteção dos seus direitos. Contudo, esta almejada participação não pode ser a mera imposição de verdades, a síntese sem antítese.

Para isso, entretanto, merece revisão a tradicional compreensão do princípio do contraditório. Por contraditório entende-se a garantia de participação dos destinatários dos efeitos do ato final em sua fase preparatória, da simétrica paridade das suas posições e da mútua implicação das suas atividades destinadas, respectivamente a promover e impedir a emanação do provimento. Nestes termos, o princípio do contraditório não deve ser oportunizado em um único momento singular; ou melhor, o princípio do contraditório não é garantia que se esgote no cumprimento de um único ato. Ele requer toda uma série de manifestações e uma série de normas disciplinadoras, em conexão entre si, de forma a reger a seqüência de seu desenvolvimento. Sem maiores rodeios, o princípio do contraditório importa a condução dialética do processo, haja vista, que compreende o acesso a qualquer informação necessária à defesa, bem como a condição de reação [facultativa] das partes. Através do princípio do contraditório é que se estabelece racionalmente uma relação comunicativa [argumentativa] entre os destinatários do provimento jurisdicional, tanto na esfera administrativa quanto na judicial. Recordando as aulas de Física, o princípio do contraditório necessita urgentemente ser praticado como uma força centrípeta que, por sua dinâmica tem o condão de trazer todas as considerações para o 
núcleo do processo. No desenvolvimento do devido processo legal o princípio do contraditório constitui-se em instrumento portador da garantia inafastável de se produzir defesa em sua forma ampla, de se questionar a imparcialidade do julgador, de se exigir a tutela jurisdicional constitucionalmente assegurada.

Para que os cidadãos reconheçam a importância das normas e das decisões jurisdicionais é de fundamental importância que participem da sua construção, pois como principais destinatários delas precisam antes de tudo de informação e de tomada da consciência. Neste cenário, as figuras petrificadas ganham vida, de sorte que o direito e o ideal de justiça transcendem o caráter de ficção para invadir a realidade. Com efeito, quanto mais a jurisdição abre-se à sociedade e aos indivíduos, mais legitimidade tende a concentrar às suas decisões, conforme Bolzan:

[...] e, com isso, maior grau de confiabilidade e respeito poderá obter no meio social, ao mesmo tempo em que se torna mais suscetível aos influxos e refluxos das dinâmicas e idiossincrasias sociais, sem que, com isso, se esteja supondo a possibilidade de ruptura do pacto político-constitucional em contradição com o projeto finalístico que nele se contém, bem como se perspective qualquer possibilidade de promover-se uma releitura da 'tradição' do constitucionalismo e da cultura que lhe constitui.

É por tais razões que: em se abraçar a ideia de status activus processualis dá-se voz à cidadania. $\mathrm{O}$ indivíduo sai da letargia para o exercício efetivo de uma democracia humanista e inclusiva. Sem esta via de inclusão, participação e deliberação toda e qualquer decisão jurisdicional será mera ficção jurídica.

\section{CONCLUSÃO}

O momento histórico-jurídico hodierno autoriza compreender que a efetivação do Estado Democrático de Direito é carente de bases de inclusão e participação dos indivíduos - num passo avante à típica ideia de participação cidadã de matriz liberal-burguesa. Por muito tempo pensou-se tão-somente na participação no processo, sem considerar o desafio da inclusão dos indivíduos que caracteriza nosso sistema de foraclusão. Aqui, duas considerações merecem destaque, ainda que de forma sucinta. Um Estado Democrático de Direito não se resume em eleições regulares e no lema governo do povo, pelo povo, para o povo. A democracia e consequentemente o Estado Democrático de Direito 
implica, além da tradicional noção de procedimento, no reconhecimento da desconcentração e da difusão do poder. Por tais razões, a atuação jurisdicional já não se sintetiza na figura do juiz boca da lei, alheio com as situações extraprocessuais, pré-ocupado com a pacificação social mas castrado do contato com a sociedade.

Os novos conflitos impõem ao Poder Judiciário a necessidade de desneutralização. Ainda que sem entrar nas discussões procedimentalismo versus substancialismo é possível vislumbrar uma postura ativa da jurisdição para a efetividade plena do ordenamento jurídico. Não há espaço para o juiz Pilatos. Esses novos conflitos reclamam uma nova forma de tutela jurisdicional. A matriz liberal-individual-normativista precisa ceder lugar ante as exigências de solidariedade, inclusão e participação.

Para tanto, o processo jurisdicional deve ser compreendido como um espaço democrático de participação e inclusão dos indivíduos à luz do Estado Democrático de Direito. Assim, para a satisfação de tal desiderato, a noção do status activus processualis carece ser resgatada. É esta a condição para que os indivíduos tenham um lugar de fala no processo, onde possam deliberar e apresentar suas alegações via contraditório em simétrica paridade de oportunidades. Em grande parte, a crise de legitimidade que atinge as decisões jurisdicionais decorre da forma burocrática [kafkaniana] pela qual o processo é conduzido. No Estado Democrático de Direito o processo jurisdicional passa a ser um meio propício de operar a ação do Estado na realização dos objetivos traçados pela Constituição.

No Brasil, contudo, a ideia de status activus processualis suplica além de um amplo acesso à justiça de instrumentos positivos de equalização das posições culturais, sociais e econômicas dos envolvidos. A tutela jurisdicional não pode ser privilégio de uma minoria ou, condicionada por múltiplas situações de bloqueio. De igual sorte é cristalina a impotência da teoria de que a função do Poder Judiciário deve ser a de cuidar exclusivamente dos procedimentos democráticos.

Em uma sociedade nitidamente excludente defender piamente a onipotência dos procedimentos equivale, metaforicamente, a construção de uma residência que se principia pela colocação das telhas, ou ao bolo que se inicia pelo posicionamento da cereja. Em sede de processo jurisdicional certos valores e obrigações inscritos na Constituição precisam de satisfação. Aos procedimentos deve ser adicionada uma teoria de direitos e valores substantivos para que se efetive uma participação democrática na tomada das decisões.

SCIENTIA IURIS, Londrina, v.16, n.2, p.69-82, dez.2012 
Cabe determinar que o eixo substancialista não ignora a importância do respeito aos procedimentos, muito ao contrário, questiona, isto sim, a ideia de que o procedimento se faz pelo procedimento. Além de valorizar os procedimentos, destaca a importância dos valores substantivos, por meio da interpretação que deve ser feita jurisdicionalmente, com o objetivo de garantir a manutenção da vontade dos indivíduos consagrada constitucionalmente.

Por tais razões, a ideia de status activus processualis tem uma afeição mais próxima com a teoria substancialista, uma vez que a defesa de valores morais presentes na Constituição possibilita a inclusão e a participação dos indivíduos nos procedimentos jurisdicionais, sem nenhum repúdio ao procedimentalismo. Considerando a satisfação plena das promessas da modernidade em alguns países, é possível concordar com a irrelevância da teoria substancialista e advogar a função procedimental ao Poder Judiciário, mas este não é o caso brasileiro.

Nessa exata senda, faz-se imperioso concordar com Streck, para quem, no plano da ação cotidiana dos juristas, em solo brasileiro, nem o eixo procedimentalismo nem o substancialismo ocupam espaço de preponderância. A prática substancialista ainda está longe, em face da inefetividade de grande parcela dos direitos sociais constitucionalmente consagrados e da postura adotada pelo Judiciário na apreciação de mandados de injunção e ações de inconstitucionalidade por omissão, bem como, a baixa filtragem hermenêutico-constitucional das normas anteriores a Carta de 1988. Noutro vértice, a submissão do Legislativo à costumeira e reiterada utilização de Medidas Provisórias por parte do Executivo, somada a crescente governabilidade via "decretos", demonstra as incongruências da criação democrática de direitos e a preservação dos procedimentos legislativos aptos a conferir autonomia aos cidadãos, como desejam os procedimentalistas, em especial, Habermas.

Enfim, a democracia envolve a garantia de cada indivíduo de participar e influenciar na sociedade e nas suas condições de vida, devendo o Estado incentivar e promover a inclusão e a participação nas ações sociais. Somente quem está efetivamente incluído na ordem constitucional possui interesse na defesa da Constituição. Desta forma, a proposta de status activus processualis transcende a análise de pertinência ao eixo procedimentalista ou ao eixo substancialista em favor de uma postura ativa de proteção do Estado Democrático de Direito. 


\section{REFERENCIAS}

ABREU, Pedro Manoel. Acesso à justiça e juizados especiais. O desafio histórico da consolidação de uma justiça cidadã no Brasil. 2. ed. Florianópolis: Conceito, 2008.

Processo e democracia. O processo jurisdicional como um locus da democracia participativa e da cidadania inclusiva no estado democrático de direito. São Paulo: Conceito, 2011.

CAPPELLETTI, Mauro. Juízes legisladores? Porto Alegre: SAFE, 1999.

DWORKIN, Ronald. O império do direito. São Paulo: Martins Fontes, 1999.

FAZZALARI, Elio. Instituições de direito processual. Trad. Eliane Nassif. Campinas: Bookseller, 2006.

FERRER, Gabriel Real; CRUZ, Paulo Márcio. Los nuevos escenarios transnacionales y las democracias asimétricas. Revista Jurídicas -

Universidad de Caldas. Caldas (Colômbia), a.7, n.2, p.23-52, jul-dez 2010.

GARAPON, Antoine. O juiz e a democracia: o guardião de promessas.

2. ed. Trad. Maria Luiza de Carvalho. Rio de Janeiro: Renavan, 2001.

GUERRA FILHO, Willis Santiago. A jurisdição constitucional no Brasil: observações a partir do direito constitucional comparado. Anuário Iberoamericano de Direito Constitucional - Centro de Estudios Políticos y Constitucionales. Madrid: v. 5, p. 151-168, 2001.

HÄBERLE, Peter. Teoria de la constitución como ciencia de la cultura. Madrid: Tecnos, 2000.

HABERMAS, Jürgen. Direito e democracia: entre facticidade e validade. 2. ed. Trad. Flavio Beno Siebeneichler. Rio de Janeiro: Tempo Brasileiro, 2003, v. II. 
Acción comunicativa y razón sin transcedencia. Trad. Pere Fabra Abat. Barcelona: Paidós, 2002.

LUHMANN, Niklas. Legitimação pelo procedimento. Brasília: UnB, 1980.

LEAL, Mônica Clarissa Hennig. A noção de status activus processualis como fundamento para a operacionalização de uma jurisdição constitucional aberta. LEAL, Rogério Gesta. Direitos sociais e políticas públicas: desafios contemporâneos. Santa Cruz do Sul: EDUNISC, 2007.

MARCELLINO JUNIOR, Julio Cesar. O princípio constitucional da eficiência administrativa: (des)encontros entre economia e direito. Florianópolis: Habitus, 2009.

MIGLINO, Arnaldo. La democrazia come diffusione del potere. Archivio giuridico. Roma, v. CCXXX, n.1, p.55-73, 2010.

MORAIS, José Luiz Bolzan de et. al. Jurisdição constitucional e participação cidadã: por um processo formal e substancialmente vinculado aos princípios político-constitucionais! MACHADO, Felipe Daniel Amorim; OLIVEIRA, Marcelo Andrade Cattoni de (Orgs.). Constituição e processo: a contribuição do processo ao constitucionalismo democrático brasileiro. Belo Horizonte: DelRey/IHJ, 2009.

MÜLLER, Friedrich. Que grau de exclusão social ainda pode ser tolerado por um sistema democrático? PIOVESAN, Flávia (Coord.). Direitos humanos, globalização econômica e integração regional. Desafios do direito constitucional internacional. São Paulo: Max Limonad, 2002.

OLIVEIRA, Marcelo Andrade Cattoni de. Direito constitucional. Belo Horizonte: Mandamentos, 2002.

ROSA, Alexandre Morais da. Decisão penal: a bricolage de significantes. Rio de Janeiro: Lúmen Juris, 2006. 
STAFFEN, Márcio Ricardo; CADEMARTORI, Daniela Mesquita Leutchuk de. A função democrática do princípio do contraditório no âmbito do processo administrativo disciplinar: aproximações entre Elio Fazzalari e Jürgen Habermas. Revista Brasileira de Direitos Fundamentais \& Justiça Programa de Pós-Graduação Stricto Sensu em Direito - PUC/RS. Porto Alegre, a.4, n.12, p.229-245, jul. set. 2010.

--STRECK, Lenio Luiz. Hermenêutica jurídica e(m) crise. Uma exploração hermenêutica da construção do direito. 8. ed. Porto Alegre: Livraria do Advogado, 2009.

. O papel da jurisdição constitucional da realização dos direitos sociais-fundamentais. In: SARLET, Ingo Wolfgang. Direitos fundamentais sociais: estudos de direito constitucional, internacional e comparado. Rio de Janeiro: Renovar, 2003.

VIANNA, Luiz Werneck, et. al. A judicialização da política e das relações sociais no Brasil. Rio de Janeiro: Revan, 1999.

WARAT, Luis Alberto. O ofício do mediador. Florianópolis: Habitus, 2001.

Recebido em: 2012-04-08 Aprovado para publicação em: 2012-12-11

Como citar: STAFFEN, Márcio Ricardo; ABREU, Pedro Manoel. Reflexões sobre o modelo participativo de processo jurisdicional brasileiro. Scientia Iuris, Londrina, v.16, n.2, p.69-82, dez. 2012. DOI: 10.5433/2178-8189.2012v16n2p69. 